Research Paper

\title{
The addition of metformin to systemic anticancer therapy in advanced or metastatic cancers: a meta- analysis of randomized controlled trials
}

\author{
Hyeong Su Kim¹, Jung Han Kim ${ }^{1 凶}$, Hyun Joo Jang ${ }^{2 \bowtie}$ and Jin Lee ${ }^{2}$ \\ 1. Division of Hemato-Oncology, Department of Internal Medicine, Hallym University Medical Center, Hallym University College of Medicine, Seoul 07441, \\ Republic of Korea. \\ 2. Division of Gastroenterology, Department of Internal Medicine, Dongtan Sacred-Heart Hospital, Hallym University Medical Center, Hallym University \\ College of Medicine, Hwasung 18450, Gyeonggi-Do, Republic of Korea. \\ $\square$ Corresponding authors: Hyun Joo Jang and Jung Han Kim. Department of Internal Medicine, Hallym University Medical Center, Hallym University College \\ of Medicine, Seoul, Republic of Korea. E-mail: jhj1229@hallym.or.kr (HJ Jang); harricil@hallym.or.kr (JH Kim). \\ (c) The author(s). This is an open access article distributed under the terms of the Creative Commons Attribution License (https://creativecommons.org/licenses/by/4.0/). \\ See http://ivyspring.com/terms for full terms and conditions.
}

Received: 2020.07.05; Accepted: 2020.09.01; Published: 2020.09.12

\begin{abstract}
Preclinical studies have demonstrated that metformin has anticancer properties and act in additive or synergistic way when combined with anticancer agents. We conducted this meta-analysis of randomized clinical trials to evaluate the effect of metformin added to systemic anticancer therapy in patients with advanced or metastatic cancer. A computerized systematic electronic search was performed using PubMed, PMC, EMBASE, Cochrane Library, and Web of Science databases (up to June 2020). From nine randomized clinical trials, 821 patients were included in the pooled analyses of odds ratios (ORs) with 95\% confidence intervals (Cls) for overall response rate (ORR) and hazard ratios (HRs) with $95 \% \mathrm{Cls}$ for progression-free survival (PFS) and overall survival (OS). The concomitant use of metformin with systemic anticancer therapy did not increase tumor response (the pooled OR of ORR $=1.23,95 \% \mathrm{Cl}$ : 0.89-1.71, $p=0.21$ ), compared with anticancer therapy alone. In terms of survival, metformin added to anticancer agents failed to prolong PFS ( $\mathrm{HR}=0.95,95 \% \mathrm{Cl}: 0.75-1.21, p=0.68)$ and $\mathrm{OS}(\mathrm{HR}=0.97,95 \%$ $\mathrm{Cl}: 0.80-1.16, p=0.71)$. In conclusion, this meta-analysis of randomized clinical trials indicates that the addition of metformin to systemic anticancer therapy has no clinical benefits in patients with advanced or metastatic cancer.
\end{abstract}

Key words: metformin, cancer, randomized controlled study, prognosis, meta-analysis

\section{Introduction}

Metformin is a biguanide that is commonly prescribed in the treatment of type 2 diabetes mellitus (DM). The mechanism of action by which metformin lowers blood glucose level is not fully understood, but it is known to decrease hepatic gluconeogenesis and increase insulin sensitivity [1]. Recently, it has raised worldwide attention for its potential antitumor effects. Epidemiologic studies have reported that metformin use was associated with reduced risk of cancers among diabetic patients [2-6]. In addition, experimental studies have demonstrated that metformin has antitumor effects in vivo and in vitro, which may repress proliferation of cancer cells and induce apoptosis, autophagy, and cell cycle arrest [7-11].

Metformin may act in additive or synergistic way when combined with anticancer therapy. Indeed, many preclinical studies have demonstrated the synergistic interaction of metformin and chemotherapeutic agents, such as gemcitabine [12], docetaxel [13], and platinum [14], or epidermal growth factor receptor-tyrosine kinase inhibitors (EGFR-TKIs) [15]. Observational studies have also found the beneficial effects of metformin use for diabetic patients with advanced cancer [16-18]. In a retrospective study of breast cancer (BC) patients treated with neoadjuvant chemotherapy, a high 
frequency of complete pathological responses was noted in diabetic patients treated with metformin, compared with diabetic patients prescribed with other anti-diabetic agents while receiving chemotherapy [16]. Similarly, the analysis of data from the Surveillance, Epidemiology, and End Results registry data linked to medicare claims revealed that metformin significantly improved survival [hazard ratio $(\mathrm{HR})=0.80,95 \%$ confidence interval $(\mathrm{CI})$ : 0.71-0.89] in metastatic non-small-cell lung cancer (NSCLC) patients with DM even after adjusting for demographics, diabetes severity and treatment, cancer characteristics, and oncologic treatment [17]. Other retrospective study of patients with advanced pancreatic cancer (PC) undergoing chemotherapy, metformin therapy itself conferred better overall survival (OS) in comparison within DM patients (HR $=0.693,95 \%$ CI: 0.492-0.977, $P=0.036$ ) [18]. In addition, single-arm phase II trial reported that metformin combined with 5-fluorouracil showed a modest but intriguing activity in patients with refractory metastatic colorectal cancer [19].

Based on these results, several randomized controlled trials have been conducted to investigate the effect of adding metformin to anticancer agents in patients with various types of cancer [20-30]. Contrary to the observational studies, the most randomized trials failed to demonstrate a significant improvement of clinical outcomes in patients treated with metformin in combination with systemic anticancer treatment [20-27]. However, the results were inconclusive because most studies were phase II trials with a small sample size. Therefore, we conducted this meta-analysis of randomized clinical trials to evaluate the effect of adding metformin to systemic anticancer therapy.

\section{Materials and methods}

\section{Search strategy}

This meta-analysis followed the Preferred Reporting Items for Systematic Reviews and Meta-Analyses (PRISMA) guidelines [31,32]. A computerized systematic electronic search was performed using PubMed, PMC, EMBASE, Cochrane Library, and Web of Science databases (up to June 2020). The search included the following terms: "metformin" AND "carcinoma" or "cancer" or "neoplasm" or "malignancy" AND "randomized." Besides, manual searching of references in identified studies and relevant reviews was performed to retrieve every potential article.

\section{Inclusion criteria}

Eligible studies should meet the following inclusion criteria: (i) randomized clinical trials in human cancers; (ii) randomization of patients to systemic anticancer therapy with or without metformin; (iii) sufficient data for odds ratio (OR) with $95 \%$ confidence interval (CI) for overall response rate (ORR) and/or hazard ratio (HR) with 95\% CI for progression-free survival (PFS) or OS; (iv) trials published only in peer-reviewed journals. There were no language or district restrictions.

\section{Exclusion criteria}

We excluded: (i) non-randomized trials; (ii) cohorts with no control groups; (iii) trials that did not report essential outcomes (ORR, OS, or PFS); (iv) studies adding metformin to local anticancer treatments and, (v) abstracts not formally published in peer-reviewed journal.

\section{Data extraction}

A pair of investigators (JH Jang and HS Kim) independently carried out the abstract screening, full text reviewing, and data extraction. Any disagreements were resolved by discussion, with input from the other investigator (JH Kim).

The following data were extracted from the included articles: first author, year of publication, trial phase, number of patients, primary endpoint, treatment setting and regimen, intervention in the control group, adverse events (AEs), ORR, and PFS and OS along with their $95 \% \mathrm{CI}$. If several estimations were conducted in one study, the most powerful result was selected (i.e., the multivariate regression would be given priority, and the univariate regression was superior to the unadjusted Kaplan-Meier analysis).

\section{Statistics}

ORs, and HRs along with their 95\% CIs used in the analyses were directly extracted from the original articles. If these statistical variables were not given explicitly in an article, they were calculated from available numerical data using methods reported by Parmar et al. [33].

The RevMan version 5.3 was used to combine the data. The heterogeneity across studies was estimated by using the $\mathrm{I}^{2}$ inconsistency test and chi-square-based Cochran's $Q$ statistic test. The fixed-effect model based on Mantel-Haenszel method was selected when there was no substantial heterogeneity $\left(p \geq 0.1\right.$ or $\left.\mathrm{I}^{2} \leq 50 \%\right)$. When significant heterogeneity was observed $\left(p<0.1\right.$ and $\left.\mathrm{I}^{2}>50 \%\right)$, the random-effects model based on DerSimonian-Laird method was used. We also planned to perform additional subgroup analyses to identify the source of heterogeneity. Sensitivity analysis was conducted to assess the impact of each study on the pooled HR and heterogeneity by removing one study at a time. 
Outcomes are shown as forest plots with diamonds representing the estimate of the pooled effect. The line of no impact is number one for binary outcomes, which depicts statistical significance if not crossed by the diamond [34]. The pooled OR $<1.0$ and $\mathrm{HR}<1.0$ implies higher rate and better survival, respectively, for the addition of metformin to anticancer therapy. The significance of the pooled HR and OR was determined by the Z-test, and the level of statistical significance was established as $p<0.05$. Publication biases were evaluated graphically by the Begg's funnel plot and quantified by the Egger's test to assess funnel plot asymmetry $[35,36]$.

\section{Quality of the included studies}

The methodological quality of the randomized trials was scored by the Jadad five-item scale, assessing randomization, double blinding process, and withdrawals or dropouts [37]. The final score ranged from 0 to 5 , with low quality studies having a score $\leq 2$ and high quality studies having a score of $\geq 3$.

\section{Ethics}

This study did not require the approval of the institutional ethics committee because it was a meta-analysis with systematic review of previously published articles.

\section{Results}

\section{Results of search}

The flow diagram of the search process is shown in Figure 1. A total of 224 potentially relevant articles were initially retrieved. Out of them, 204 articles were excluded after careful reviewing of the titles and abstracts. Of remaining 20 potentially eligible studies, 11 were further excluded by the inclusion or exclusion criteria. Eventually, nine randomized, clinical trials fulfilling the eligibility criteria were included in the meta-analysis [20-28].

\section{Characteristics of the included studies}

Table 1 summarizes the major characteristics and clinical outcomes of the nine included studies. All the studies were randomized phase II trials. The studies enrolled patients with advanced or metastatic PC $[20,22]$, BC $[23,25,26]$, and NSCLC $[21,24,27,28]$. The dose of metformin used was from $500 \mathrm{mg} / \mathrm{d}$ to 2 $\mathrm{g} / \mathrm{d}$. Jadad score was more than 3 in all the studies, indicating a good quality of each study. From the nine studies, 821 patients were included in the metaanalysis.

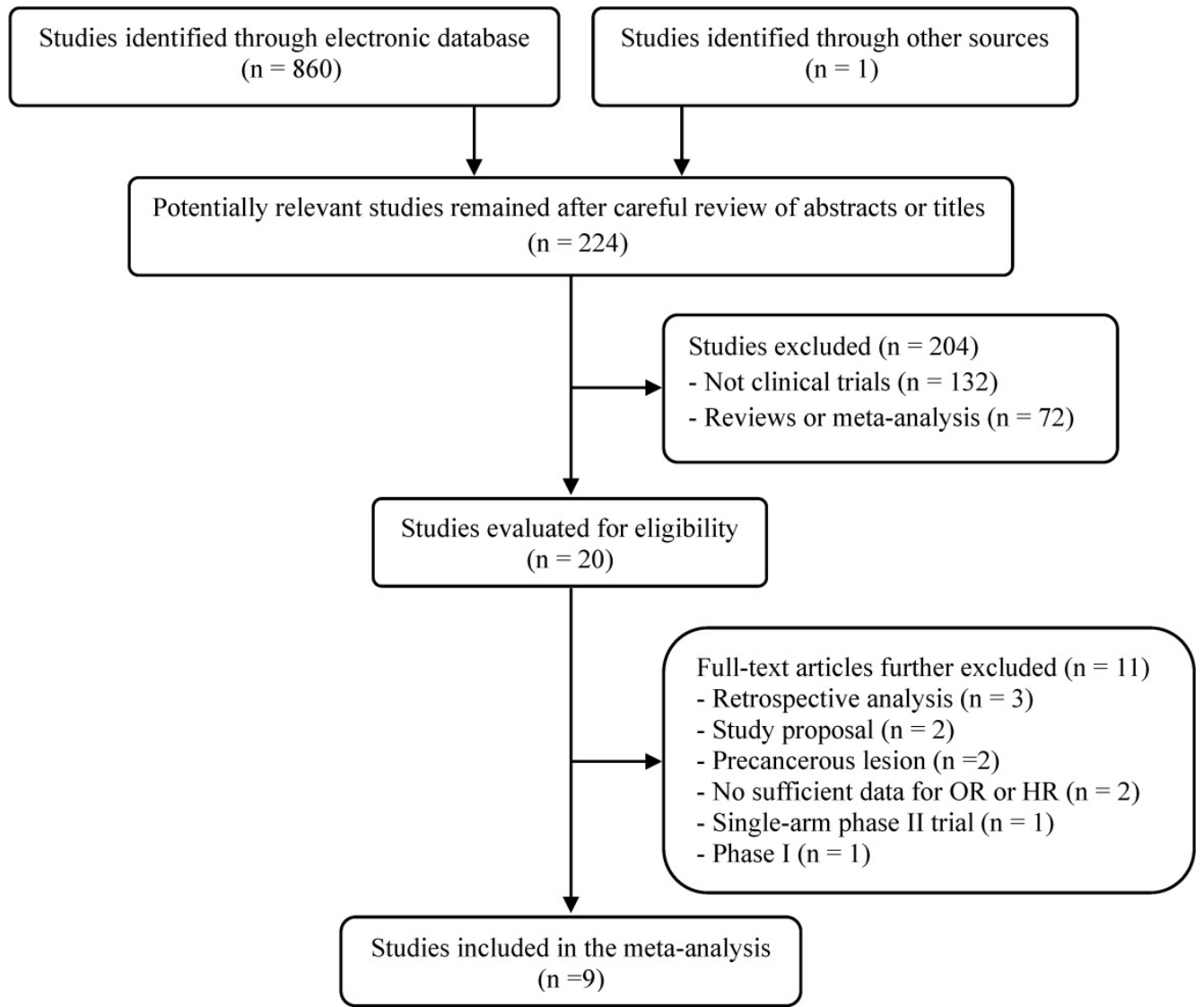

Figure 1. Flow diagram of search process. 
Table 1. Nine randomized controlled trials of metformin addition to systemic anticancer therapy

\begin{tabular}{|c|c|c|c|c|c|c|c|c|c|c|c|c|c|}
\hline $\begin{array}{l}\text { First author } \\
\text { (year) [ref.] }\end{array}$ & Cancer type & Phase & Setting & Treatment arm & $\begin{array}{l}\text { No. of } \\
\text { patients }\end{array}$ & $\begin{array}{l}\text { Primary } \\
\text { endpoint }\end{array}$ & ORR & AEs & $\begin{array}{l}\mathrm{mPFS} \\
(\mathrm{mo})\end{array}$ & $\begin{array}{l}\text { HR for PFS } \\
(95 \% \mathrm{CI})\end{array}$ & $\begin{array}{l}\mathrm{mOS} \\
(\mathrm{mo})\end{array}$ & $\begin{array}{l}\text { HR for OS } \\
(95 \% \mathrm{CI})\end{array}$ & $\begin{array}{l}\text { Jadad } \\
\text { score }\end{array}$ \\
\hline \multirow[t]{2}{*}{$\begin{array}{l}\text { Kordes } \\
(2015)[20]\end{array}$} & \multirow[t]{2}{*}{ PC } & \multirow[t]{2}{*}{ II } & \multirow[t]{2}{*}{$1^{\text {st }}$} & $\begin{array}{l}\text { Gemcitabine/erlotinib + } \\
\text { metformin (up to } 2 \mathrm{~g} / \mathrm{d} \text { ) }\end{array}$ & 60 & \multirow[t]{2}{*}{ OS } & $8.3 \%$ & $17(28.3 \%)^{*}$ & 4.1 & \multirow[t]{2}{*}{$1.18(0.77-1.82)$} & 6.8 & \multirow[t]{2}{*}{$\begin{array}{l}1.06(0.73-1.56) \\
P=0.78\end{array}$} & \multirow[t]{2}{*}{5} \\
\hline & & & & $\begin{array}{l}\text { Gemcitabine/erlotinib + } \\
\text { placebo }\end{array}$ & 61 & & $8.3 \%$ & $28(46.7 \%)^{*}$ & 5.4 & & 7.6 & & \\
\hline \multirow[t]{2}{*}{$\begin{array}{l}\text { Sayed } \\
(2015) \text { [21] }\end{array}$} & \multirow[t]{2}{*}{ NSCLC } & \multirow[t]{2}{*}{ II } & \multirow[t]{2}{*}{$1^{\text {st }}$} & $\begin{array}{l}\text { Gemcitabine/cisplatin + } \\
\text { metformin }(500 \mathrm{mg} / \mathrm{d})\end{array}$ & 15 & \multirow[t]{2}{*}{ ORR } & $46.7 \%$ & $4(26.7 \%)^{\dagger}$ & 5.54 & \multirow[t]{2}{*}{$\begin{array}{l}0.35(0.12-1.05) \\
P=0.062\end{array}$} & 12 & \multirow[t]{2}{*}{$\begin{array}{l}0.32(0.08-1.34) \\
P=0.119\end{array}$} & \multirow[t]{2}{*}{3} \\
\hline & & & & Gemcitabine/cisplatin & 15 & & $13.3 \%$ & $10(66.7 \%)^{\dagger}$ & 5 & & 6.5 & & \\
\hline \multirow[t]{2}{*}{$\begin{array}{l}\text { Reni } \\
\text { (2016) [22] }\end{array}$} & \multirow[t]{2}{*}{ PC } & \multirow[t]{2}{*}{ II } & \multirow[t]{2}{*}{1 st } & PEXG + metformin $(2 \mathrm{~g} / \mathrm{d})$ & 31 & \multirow[t]{2}{*}{ PFS } & $35.5 \%$ & NA & 4.9 & \multirow[t]{2}{*}{$\begin{array}{l}1.24(0.87-1.77) \\
P=0.036\end{array}$} & 6.83 & \multirow[t]{2}{*}{$\begin{array}{l}1.09(0.64-1.84) \\
P=0.13\end{array}$} & \multirow[t]{2}{*}{3} \\
\hline & & & & PEXG & 29 & & $45 \%$ & NA & 6.1 & & 10.4 & & \\
\hline \multirow[t]{2}{*}{$\begin{array}{l}\text { Zhao } \\
\text { (2017) [23] }\end{array}$} & \multirow[t]{2}{*}{$\mathrm{H}(+) \mathrm{BC}$} & \multirow[t]{2}{*}{ II } & \multirow[t]{2}{*}{$\geq 2^{\text {nd }}$} & $\begin{array}{l}\text { Aromatase inhibitor }+ \\
\text { metformin }(1 \mathrm{~g} / \mathrm{d})\end{array}$ & 30 & \multirow[t]{2}{*}{ PFS } & $6.7 \%$ & $5(16.7 \%)^{\ddagger}$ & 4.7 & \multirow[t]{2}{*}{$\begin{array}{l}1.21(0.70-2.12) \\
P=0.48\end{array}$} & 30.9 & \multirow[t]{2}{*}{$\begin{array}{l}1.1(0.50-2.41) \\
P=0.81\end{array}$} & \multirow[t]{2}{*}{5} \\
\hline & & & & $\begin{array}{l}\text { Aromatase inhibitor + } \\
\text { placebo }\end{array}$ & 30 & & $0 \%$ & $3(10 \%)^{\ddagger}$ & 6.0 & & 32.4 & & \\
\hline \multirow[t]{2}{*}{$\begin{array}{l}\text { Marrone } \\
\text { (2018) [24] }\end{array}$} & $\begin{array}{l}\text { Non-Sq } \\
\text { NSCLC }\end{array}$ & II & $1^{\text {st }}$ & $\begin{array}{l}\text { Paclitaxel/carboplatin } \\
\text { /bevacizumab + metformin } \\
(2 \mathrm{~g} / \mathrm{d})\end{array}$ & 19 & PFS & $56 \%$ & $10(56 \%)^{ \pm}$ & 9.6 & $\begin{array}{l}0.30(0.11-0.85) \\
P=0.024\end{array}$ & 15.9 & $\begin{array}{l}0.24(0.03-1.99) \\
P=0.186\end{array}$ & 3 \\
\hline & & & & $\begin{array}{l}\text { Paclitaxel/carboplatin/ } \\
\text { bevacizumab }\end{array}$ & 6 & & $33 \%$ & $2(33 \%)^{ \pm}$ & 6.7 & & 13.9 & & \\
\hline $\begin{array}{l}\text { Nanni } \\
(2018)[25]\end{array}$ & HER2(-) BC & II & $1^{\text {st }}$ & $\begin{array}{l}\text { Doxorubicin/cyclophospha } \\
\text { mide }+ \text { metformin }(2 \mathrm{~g} / \mathrm{d})\end{array}$ & 57 & PFS & $48 \%$ & $31(54 \%)^{ \pm}$ & 9.4 & $\begin{array}{l}1.09(0.75-1.58) \\
P=0.653\end{array}$ & 34.4 & $\begin{array}{l}1.09(0.75-1.58) \\
P=0.382\end{array}$ & 3 \\
\hline & & & & $\begin{array}{l}\text { Doxorubicin/ } \\
\text { cyclophosphamide }\end{array}$ & 65 & & $49 \%$ & $47(72 \%)^{ \pm}$ & 9.9 & & 26.8 & & \\
\hline $\begin{array}{l}\text { Pimentel } \\
\text { (2019) [26] }\end{array}$ & $\mathrm{BC}$ & II & $\geq 1^{\text {st }}$ & $\begin{array}{l}\text { Chemotherapy + metformin } \\
(1.7 \mathrm{~g} / \mathrm{d})\end{array}$ & 22 & PFS & $18.2 \%$ & $7(31.8 \%)^{\neq}$ & 5.4 & $\begin{array}{l}1.2(0.63-2.31) \\
P=0.58\end{array}$ & 20.2 & $\begin{array}{l}1.68(0.79-3.55) \\
P=0.18\end{array}$ & 3 \\
\hline & & & & Chemotherapy + placebo & 18 & & $25 \%$ & $10(58.8 \%)^{\neq}$ & 6.3 & & 24.2 & & \\
\hline $\begin{array}{l}\mathrm{Li}(2019) \\
{[27]}\end{array}$ & $\begin{array}{l}\text { EGFR- } \\
\text { mutant } \\
\text { NSCLC }\end{array}$ & II & $1^{\text {st }}$ & $\begin{array}{l}\text { Gefitinib + metformin } \\
(500 \mathrm{mg}, 2 \mathrm{~g} / \mathrm{d})\end{array}$ & 112 & PFS & $66 \%$ & $26(23.4 \%)^{\neq}$ & 10.3 & $\begin{array}{l}1.04(0.75-1.45) \\
P=0.8087\end{array}$ & 22.0 & $\begin{array}{l}1.15(0.79-1.68) \\
P=0.4571\end{array}$ & 5 \\
\hline & & & & Gefitinib + placebo & 112 & & $66.7 \%$ & $21(18.9 \%)^{\neq}$ & 11.4 & & 27.5 & & \\
\hline $\begin{array}{l}\text { Arrieta } \\
(2019)[28]\end{array}$ & $\begin{array}{l}\text { EGFR-mutan } \\
\text { t lung ADC }\end{array}$ & II & $\geq 1^{\text {st }}$ & $\begin{array}{l}\text { EGFR-TKI + metformin } \\
(1 \mathrm{~g} / \mathrm{d})\end{array}$ & 69 & PFS & $71 \%$ & NA & 13.1 & $\begin{array}{l}0.60(0.40-0.94) \\
P=0.03\end{array}$ & 31.7 & $\begin{array}{l}0.5(0.28-0.90) \\
P=0.02\end{array}$ & 5 \\
\hline & & & & EGFR-TKI & 70 & & $54.3 \%$ & NA & 9.9 & & 17.5 & & \\
\hline
\end{tabular}

ADC, adenocarcinoma; EGFR, epidermal growth factor receptor; TKI, tyrosine kinase inhibitor; NSCLC, non-small-cell lung cancer; non-Sq, non-squamous; PC, pancreatic cancer; $\mathrm{H}(+)$, hormone positive; Her2(-), PEXG, cisplatin, epirubicin, capecitabine, and gemcitabine; AEs, adverse events; ORR, overall response rate; mOS, median overall survival; mPFS, median progression-free survival; mo, months; HR, hazard ratio; CI, confidence interval; NA, not available.

*Vomiting, † Nausea, \pm Grade 3-4 neutropenia, $\neq$ Arthralgia, $\neq$ Grade 3-4 adverse events.

\section{Effect of metformin addition on overall response rate}

There was no significant heterogeneity across the studies $\left(X^{2}=9.04, p=0.34, \mathrm{I}^{2}=12 \%\right)$ and the fixed-effect model was selected. The addition of metformin to anticancer agents did not increase ORR $(\mathrm{OR}=1.23,95 \% \mathrm{CI}: 0.89-1.71, p=0.21)$ (Figure 2).

\section{Effect of metformin addition on progression-free survival}

Because there was a significant heterogeneity across the studies $\left(x^{2}=16.92, p=0.03, \mathrm{I}^{2}=53 \%\right)$, the random-effects model was selected. The concomitant use of metformin and systemic anticancer therapy did not prolong significantly PFS (HR $=0.95,95 \% \mathrm{CI}$ : 0.75-1.21, $p=0.68$ ) (Figure 3A), compared with anticancer therapy alone.

\section{Effect of metformin addition on overall survival}

There was no significant heterogeneity among the studies $\left(X^{2}=12.77, p=0.12, \mathrm{I}^{2}=37\right)$ and the fixed-effect model was selected. Metformin added to anticancer therapy showed no significant impact on OS (HR $=0.97,95 \%$ CI: 0.80-1.16, $p=0.71)$ (Figure 3B).

\section{Publication bias}

Visual inspection of the funnel plots for ORR, PFS, and OS showed symmetry, suggesting there was no substantial publication bias (Figure 4). Egger's tests also indicated the absence of significant publication biases $(p=0.375$ for ORR, $p=0.095$ for PFS, and $p=0.192$ for OS).

\section{Discussion}

Based on the preclinical and epidemiologic evidence of its anticancer effect [2-11], there have been growing interests in the effect of metformin among patients with cancer. Although both retrospective data and observational studies point to metformin having a potential role in cancer treatment [16-18], the anticancer effect of this drug has not been convincingly validated in prospective trials. This meta-analysis was conducted to assess the role of metformin in the fight against cancer. The results indicated that the addition of metformin to systemic anticancer therapy was not associated with improved clinical outcomes in patients with advanced or metastatic cancer. 


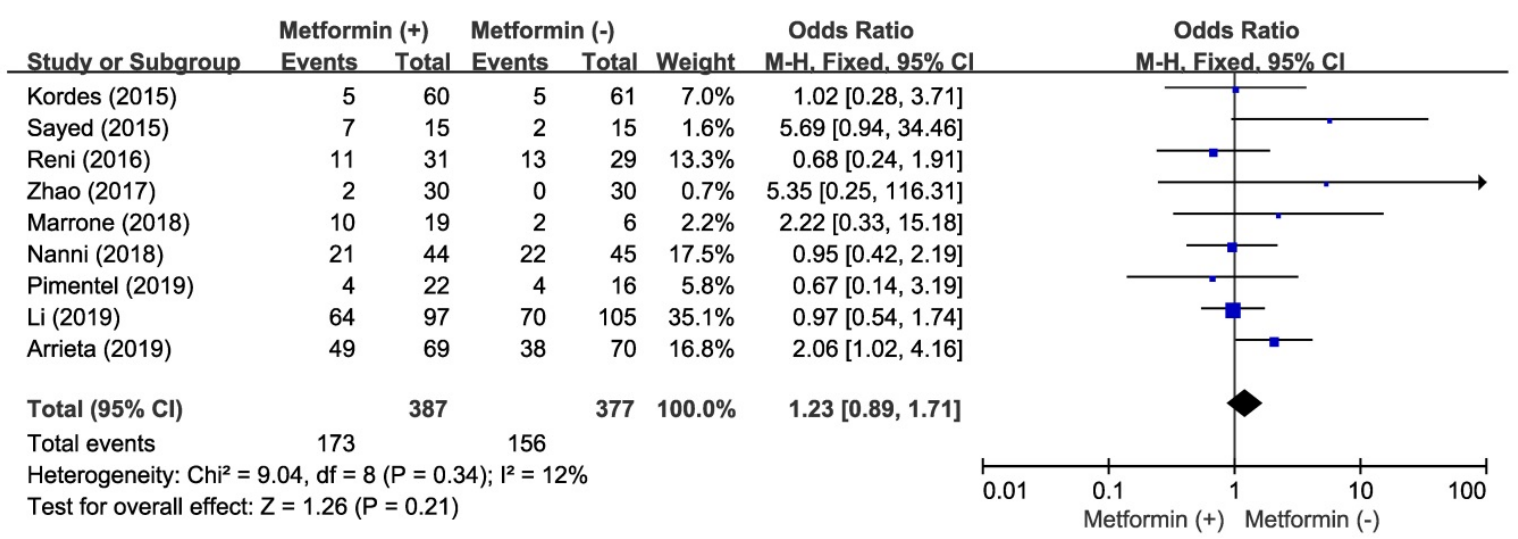

Figure 2. Forest plot for overall response rate.

A

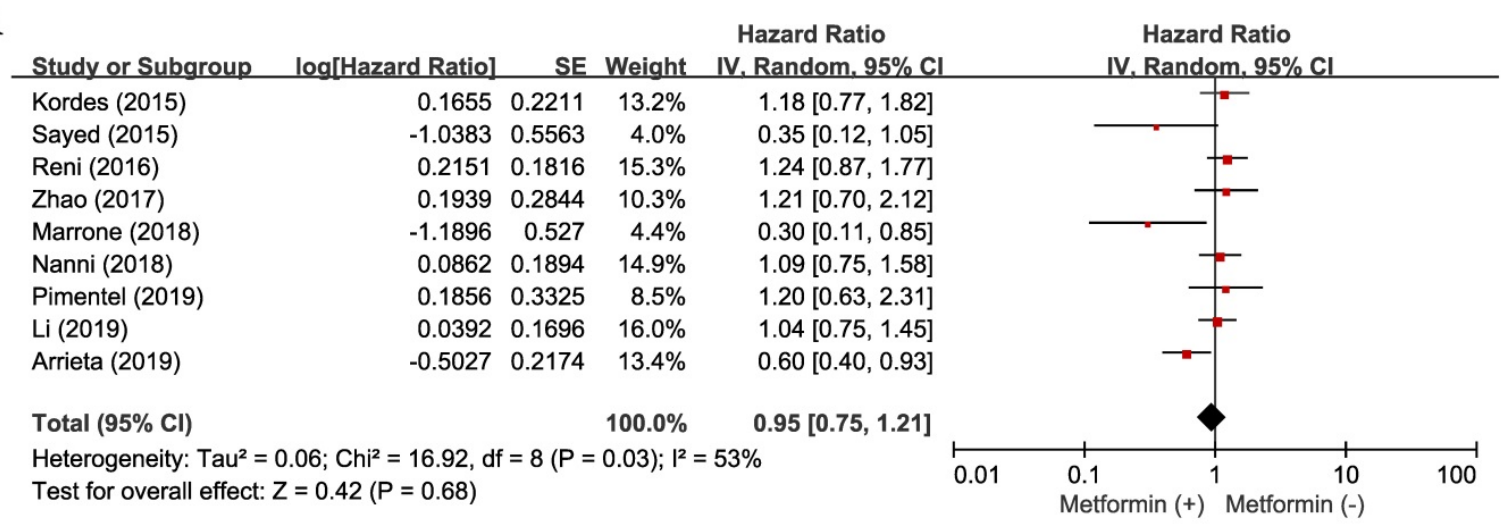

B

$\begin{array}{lrrrrrr}\text { Study or Subgroup } & \text { log[Hazard Ratio] } & \text { SE } & \text { Weight } & \begin{array}{c}\text { Hazard Ratio } \\ \text { IV. Fixed, 95\% Cl }\end{array} & \text { Hazard Ratio } \\ \text { IV. Fixed, 95\% Cl }\end{array}$

Figure 3. Forest plots for progression-free survival (A) and overall survival (B).

Metformin alters cellular energy metabolism and is known to decrease hepatic glucose production in diabetes via adenosine monophosphate kinase (AMPK) dependent and independent mechanisms $[1,38]$. The mechanisms of anticancer effects of metformin are controversial whether this activity is due to changes in the host metabolic environment or a result of direct action on cancer cells $[39,40]$. One proposed mechanism involves its effect on decreasing insulin and insulin growth factor 1 (IGF-1) and lowering the levels of IGF-1 receptor and insulin receptor. In addition, metformin may have direct inhibitory effects by activating the AMPK protein, a serine/threonine kinase activated in adenosine monophosphate rich states and hypoxia [41]. The AMPK in turn phosphorylates and inactivates proteins in the mTOR pathway, a regulatory pathway that inhibits cell proliferation, polarity, and division [42].

Consistent with experimental findings [7-11], epidemiologic and observational studies have reported that metformin was associated with reduction in the incidence of and mortality from various cancers [2-6,43]. Based on these results, several randomized controlled trials have been conducted to investigate the effect of metformin 
added to anticancer therapy in patients with advanced or metastatic cancer [20-29]. However, no studies indicated the addition of metformin to anticancer agents to be more effective, compared with anticancer therapy alone.
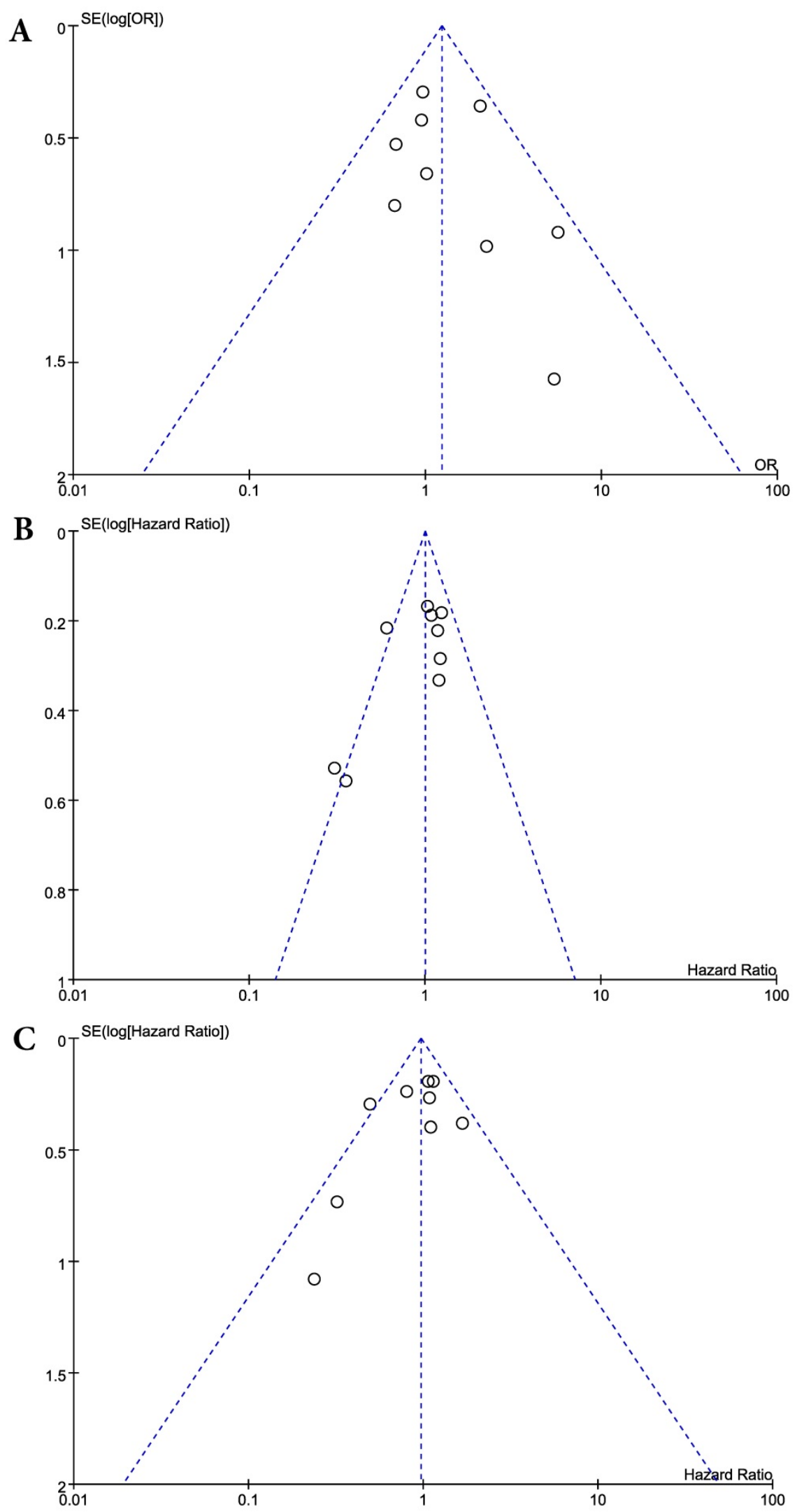

Figure 4. Funnel plots for publication bias: overall response rate (A), progression-free survival (B), and overall survival (C). 
The first randomized controlled trial of metformin addition to standard treatment was conducted by Kordes et al. in patients with advanced PC [20]. Patients were randomly assigned to receive gemcitabine and erlotinib with either metformin (up to $2 \mathrm{~g} / \mathrm{d})(\mathrm{n}=61)$ or placebo $(\mathrm{n}=60)$. However, there was no difference on OS between the two groups (median 7.6 in the placebo group vs. 6.8 months in the metformin group, $p=0.78$ ). Reni et al. performed an open-label, randomized phase II trial in patients with metastatic PC [22]. They randomly assigned 60 patients to receive cisplatin, eiprubicin, capecitabine and gemcitabine $(\mathrm{PEXG})$ with $(\mathrm{n}=31)$ or without metformin $(2 \mathrm{~g} / \mathrm{d})(\mathrm{n}=29)$. The trial was terminated early for futility after the preplanned interim analysis. Despite the differences in the study design between the two trials (e.g., disease stage, chemotherapeutic agents, blinding with use of placebo, interim analysis with early termination) [20,22], the results were consistent with no significant PFS and OS benefits in the metformin group. A couple of meta-analyses in PC suggested the beneficial effect of metformin on survival $[44,45]$. However, they included not only randomized trials but also observational studies.

Several clinical studies have also suggested the antitumor effects of metformin in patients with BC. A retrospective study reported that patients treated with metformin during neoadjuvant chemotherapy achieved a higher pathologic complete response $(\mathrm{pCR})$ rate than diabetic and non-diabetic patients not administered metformin [16]. In the METTEN study assessing the efficacy of adding metformin to neoadjuvant chemotherapy plus trastuzumab in early HER2-positive BC, however, metformin addition failed to show statistically significant superiority in the rate of $\mathrm{pCR}(66 \%$ vs. $59 \%, p=0.589)$ and breastconserving surgery $(79 \%$ vs. $59 \%, p=0.089)$ [29]. There are three randomized phase II trials of metformin added to systemic anticancer therapy in patients with metastatic BC $[23,25,26]$. Zhao et al. randomly assigned 60 postmenopausal patients with pre-treated hormone receptor positive metastatic $B C$ to receive aromatase inhibitor plus metformin $(n=30)$ or placebo $(n=30)$ [23]. Nanni et al. investigated the efficacy of metformin plus chemotherapy $(n=57)$ versus chemotherapy alone $(n=65)$ in the first-line treatment of HER2-negative metastatic BC [25]. Pimentel et al. conducted a randomized, placebocontrolled phase II trial to investigate the effect of metformin added to standard chemotherapy. Forty non-diabetic patients with metastatic BC were allocated to receive chemotherapy with either metformin $(n=22)$ or placebo $(n=18)$. These phase II trials with a small sample size failed to show any clinical benefits (ORR, PFS or OS) of metformin added to endocrine therapy or chemotherapy.

In patients with NSCLC, there are two randomized trials of metformin addition to chemotherapy. Sayed et al. investigated the effects of metformin on clinical outcome of non-diabetic patients with stage IV NSCLC [21]. Thirty chemonaïve patients were randomly assigned to receive gemcitabine and cisplatin with $(n=15)$ or without metformin $(500 \mathrm{mg} / \mathrm{d})(\mathrm{n}=15)$. The ORR and median survival time were better in the metformin group ( $46.7 \%$ vs. $13.3 \%, p=0.109$ and 12 months vs. 6.5 months, $p=0.119)$, but the difference was not statistically significant in this trial with a limited number of patients. Marrone et al. conducted a randomized phase II study of metformin plus paclitaxel/carboplatin/bevacizumab in patients with chemotherapy-naïve advanced or metastatic nonsquamous NSCLC [24]. Patients were randomly assigned (3:1) to receive chemotherapy with $(\mathrm{n}=18)$ or without metformin $(2 \mathrm{~g} / \mathrm{d})(\mathrm{n}=6)$. The study was stopped early due to slow accrual and changes in the standard first-line therapy of advanced NSCLC. Although PFS was longer in the metformin group (9.6 months vs. 9.6 months, log-rank $p=0.024$ ), there was no significant differences in the secondary endpoints of ORR ( $56 \%$ vs. $35 \%, p=0.11)$ and OS (15.9 months vs. 13.9 months, $p=0.186$ ) between the two groups.

Recently, data has also shown the synergistic association between metformin and EGFR-TKIs $[15,46,47]$. A retrospective study reported that concurrent use of metformin and an EGFR-TKI conferred superior outcomes over TKI alone in terms of PFS (19 vs. 8.0 months) and OS (32 vs. 23 months). The synergistic effects may have stemmed from metformin-mediated reversal of epithelialmesenchymal transition and inhibition of interleukin-6 signaling [48]. There are two randomized trials of metformin addition to EGFRTKIs in patients with EGFR-mutant NSCLC. Li et al. conducted a randomized, double-blind phase II trial investigating the combining effects of metformin and gefitinib in patients with advanced EGFR-mutant NSCLC [27]. Treatment-naïve patients $(n=224)$ were randomly assigned to receive gefitinib plus either metformin $(n=112)$ or placebo $(n=112)$. The median PFS (10.3 vs. 11.4 months, $p=0.808)$ and median OS (22.0 vs. 27.5 months, $p=0.457$ ) were not significant different between the two groups. Arrieta et al. investigated the effects of metformin plus TKIs compared with TKI alone in patients with EGFRmutated lung adenocarcinoma [28]. Patients were randomly allocated to receive TKIs (erlotinib, afatinib, or gefitinib) plus metformin or EGFR-TKI alone. Patients allocated to receive an EGFR-TKI plus metformin showed higher ORR $(71 \%$ vs. $54.3 \%, p=$ 
0.042) than patients treated with an EGFR-TKI alone. The median PFS (13.1 vs. 9.9 months, $\mathrm{HR}=0.60 ; 95 \%$ CI: $0.40-0.94, p=0.03)$ and OS (31.7 vs. 17.5 months, $\mathrm{HR}=0.5 ; 95 \%$ CI: 0.28-0.90, $p=0.02$ ) were significantly longer in the EGFR-TKI plus metformin group compared with the EGFR-TKI monotherapy group. These findings suggest that the use of metformin as concomitant treatment of lung adenocarcinoma may be a valuable addition to improve clinical outcomes. Because this trial was neither blinded nor placebo-controlled, however, the results need to be interpreted with caution. There were also possible concerns regarding the remarkably inferior ORR and OS in the TKI alone group in comparison with historical data on the efficacy of TKIs in EGFR-mutant NSCLC.

This meta-analysis of the nine randomized clinical trials revealed that metformin in combination with systemic anticancer therapy failed to draw any clinical benefits in patients with advanced or metastatic cancer. Therapeutic intervention with metformin in cancer is an attractive option, as it is a well-tolerated oral medication with minimal side effects. The addition of metformin to anticancer agents was not associated with increased incidence of AEs in most studies. However, the combination of metformin and systemic anticancer therapy did not increase tumor response (the pooled OR of ORR = 1.23, 95\% CI: $0.89-1.71, p=0.21$ ), compared with anticancer therapy alone. In agreement with the ORR, metformin added to anticancer agents failed to prolong PFS (HR $=0.95,95 \%$ CI: 0.75-1.21, $p=0.68$ ) and $\mathrm{OS}(\mathrm{HR}=0.97,95 \% \mathrm{CI}: 0.80-1.16, p=0.71)$.

Several possibilities may explain the reasons why the addition of metformin to anticancer agents failed to show clinical benefits in patients with advanced or metastatic cancer. First, the impressive effect of metformin in reducing the incidence of and mortality from cancer might be associated with time-related biases (e.g., immortal time bias) in some observational studies [49]. Second, the dose of metformin used in the clinical trials might be insufficient. The optimal dose of metformin to display anticancer effects is not known. The metformin in the included trials were administered at the same dosage as usually used in the treatment of diabetes. With regard to the proposed direct action of metformin on tumor cells, the drug concentration achieved in tumor tissue are crucial. Therefore, conventional antidiabetes doses of metformin might fail to reach a sufficient concentration to exhibit antitumor effect. Third, as we known, cancer is not a homogeneous disease entity. Therefore, antitumor effects of metformin may significantly differ according to anatomical site and molecular type of cancers. The proposed indirect action mechanism of metformin postulates that its anticancer effects depend on the changes in the host metabolic environment, such as a reduction of insulin concentration and a resulting decrease in the activity of IR-PI3K-mTOR signaling pathway [3,50]. However, not all cancers are responsive to insulin, and there might be types of cancer in which the reduced insulin concentration is insufficient to show anticancer effects. Another hypothesis is that anticancer effect of metformin might be limited in advanced or metastatic setting with a large tumor burden [51]. Indeed, many observational or retrospective studies have reported that metformin was associated with improved outcomes when used in patients with non-metastatic disease $[16,44,45,52]$. In addition, Coyle et al. reported the meta-analysis suggesting metformin could be a useful adjuvant agent, particularly in colorectal and prostate cancer [53].

This study has some inherent limitations that need to be discussed. First, this pooled analysis included a limited number of studies with a small sample size. Second, there were no phase III trials included in the meta-analysis. Third, patients had different types of tumors and received various therapeutic regimens. We could not perform subgroup analysis according to the primary site of cancers because of the limited number of trials. Fourth, there was a significant heterogeneity across the studies when combining HRs for PFS. It could not be completely interpreted although the randomeffects model was selected.

In conclusion, this meta-analysis of randomized clinical controlled trials do not support clinical benefits of metformin added to systemic anticancer therapy in patients with advanced or metastatic cancer. However, further investigations including phase III trials are needed to resolve the issues (dose of metformin, treatment setting, particular cancer type, or immunomodulatory effect) on the addition of metformin to systemic anticancer therapy.

\section{Acknowledgments}

\section{Author contributions}

JH Kim and J Lee designed the study. HS Kim and HJ Jang searched the literatures and extracted the data. HS Kim performed the statistical analyses. HJ Jang and JH Kim wrote the manuscript.

\section{Competing Interests}

The authors have declared that no competing interest exists. 


\section{References}

1. Shaw RJ, Lamia KA, Vasquez D, Koo SH, Bardeesy N, Depinho RA, et al. The kinase LKB1 mediates glucose homeostasis in liver and therapeutic effects of metformin. Science. 2005; 310: 1642-6.

2. Evans JM, Donnelly LA, Emslie-Smith AM, Alessi DR, Morris AD. Metformin and reduced risk of cancer in diabetic patients. BMJ. 2005; 330: 1304-5.

3. Pollak MN. Investigating metformin for cancer prevention and treatment: The end of the beginning. Cancer Discov. 2012; 299: 778-90.

4. Bowker SL, Majumdar SR, Veugelers P, Johnson JA. Increased cancer-related mortality for patients with type 2 diabetes who use sulfonylureas or insulin. Diabetes Care. 2006; 29: 254-8.

5. Currie CJ, Poole CD, Gale EA. The influence of glucose-lowering therapies on cancer risk in type 2 diabetes. Diabetologia. 2009; 52: 176677.

6. Li D, Yeung SC, Hassan MM, Konopleva M, Abbruzzese JL. Antidiabetic therapies affect risk of pancreatic cancer. Gastroenterology. 2009; 137: 482-488.

7. Kisfalvi K, Eibl G, Sinnett-Smith J, Rozengurt E. Metformin disrupts crosstalk between $G$ protein-coupled receptor and insulin receptor signaling systems and inhibits pancreatic cancer growth. Cancer Res. 2009; 6: 6539-45.

8. Dowling RJ, Zakikhani M, Fantus IG, Pollak M, Sonenberg N. Metformin inhibits mammalian target of rapamycin-dependent translation initiation in breast cancer cells. Cancer Res. 2007; 67: 10804-12.

9. Gotlieb WH, Saumet J, Beauchamp MC, Gu J, Lau S, Pollak MN, et al. In vitro metformin anti-neoplastic activity in epithelial ovarian cancer. Gynecol Oncol. 2008; 110: 246-50.

10. Lee J, Hong EM, Kim JH, Jung JH, Park SW, Koh DH, et al. Metformin induces apoptosis and inhibits proliferation through the AMP-activated protein kinase and insulin-like growth factor 1 receptor pathways in the bile duct cancer cells. J Cancer 2019; 10: 1734-44.

11. Morran DC, Wu J, Jamieson NB, Mrowinska A, Kalna G, Karim SA, et al. Targeting mTOR dependency in pancreatic cancer. Gut. 2014; 63: 1481-9.

12. Qian W, Li J, Chen K, Jiang Z, Cheng L, Zhou C, et al. Metformin suppresses tumor angiogenesis and enhances the chemosensitivity of gemcitabine in a genetically engineered mouse model of pancreatic cancer. Life Sci. 2018; 208: 253-61.

13. Mayer MJ, Klotz LH, Venkateswaran V. Evaluating Metformin as a Potential chemosensitizing agent when combined with docetaxel chemotherapy in castration-resistant prostate cancer cells. Anticancer Res. 2017; 37: 6601-7.

14. Wang F, Ding X, Wang T, Shan Z, Wang J, Wu S, et al. Metformin inhibited esophageal squamous cell carcinoma proliferation in vitro and in vivo and enhanced the anti-cancer effect of cisplatin. PLoS One. 2017; 12: $\mathrm{e} 0174276$

15. Pan YH, Jiao L, Lin CY, Lu CH, Li L, Chen HY, et al. Combined treatment with metformin and gefitinib overcomes primary resistance to EGFR-TKIs with EGFR mutation via targeting IGF-1R signaling pathway. Biologics. 2018; 12: 75-86.

16. Jiralerspong, S.; Palla, S.L.; Giordano, S.H.; Meric-Bernstam, F.; Liedtke, C.; Barnett, C.M.; Hsu, L.; Hung, M.C.; Hortobagyi, G.N.; Gonzalez-Angulo, A.M. Metformin and pathologic complete responses to neoadjuvant chemotherapy in diabetic patients with breast cancer. J Clin Oncol 2009; 27: 3297-3302.

17. Lin JJ, Gallagher EJ, Sigel K, Mhango G, Galsky MD, Smith CB, et al. Survival of patients with stage IV lung cancer with diabetes treated with metformin. Am J Respir Crit Care Med. 2015; 191: 448-54.

18. Choi Y, Kim TY, Oh DY, Lee KH, Han SW, Im SA, et al. The impact of diabetes mellitus and metformin treatment on survival of patients with advanced pancreatic cancer undergoing chemotherapy. Cancer Res Treat. 2016; 48:171-9.

19. Miranda VC, Braghiroli MI, Faria LD, Bariani G, Alex A, Bezerra Neto JE, et al. Phase 2 trial of metformin combined with 5 -fluorouracil in patients with refractory metastatic colorectal cancer. Clin Colorectal Cancer. 2016; 15: 321-8.e1

20. Kordes S, Pollak MN, Zwinderman AH, Mathôt RA, Weterman MJ, Beeker A, et al. Metformin in patients with advanced pancreatic cancer: a double-blind, randomised, placebo-controlled phase 2 trial. Lancet Oncol. 2015; 16: 839-47.

21. Sayed R, Saad AS, El Wakeel L, Elkholy E, Badary O. Metformin addition to chemotherapy in stage IV non-small cell lung cancer: an open label randomized controlled study. Asian Pac J Cancer Prev. 2015; 16: 6621-6.

22. Reni M, Dugnani E, Cereda S, Belli C, Balzano G, Nicoletti R, et al. (Ir)relevance of metformin treatment in patients with metastatic pancreatic cancer: an open-label, randomized phase II trial. Clin Cancer Res. 2016; 22: 1076-85.
23. Marrone KA, Zhou X, Forde PM, Purtell M, Brahmer JR, Hann CL, et al. A randomized phase II study of metformin plus paclitaxel/carboplatin/ bevacizumab in patients with chemotherapy-naïve advanced or metastatic nonsquamous non-small cell lung cancer. Oncologist. 2018; 23: 859-65.

24. Zhao Y, Gong C, Wang Z, Zhang J, Wang L, Zhang S, et al. A randomized phase II study of aromatase inhibitors plus metformin in pre-treated postmenopausal patients with hormone receptor positive metastatic breast cancer. Oncotarget. 2017; 8: 84224-36.

25. Nanni O, Amadori D, De Censi A, Rocca A, Freschi A, Bologna A, et al. Metformin plus chemotherapy versus chemotherapy alone in the first-line treatment of HER2-negative metastatic breast cancer. The MYME randomized, phase 2 clinical trial. Breast Cancer Res Treat. 2019; 174: 433-42.

26. Pimentel I, Lohmann AE, Ennis M, Dowling RJO, Cescon D, Elser C, et al. A phase II randomized clinical trial of the effect of metformin versus placebo on progression-free survival in women with metastatic breast cancer receiving standard chemotherapy. Breast. 2019; 48: 17-23.

27. Li L, Jiang L, Wang Y, Zhao Y, Zhang XJ, Wu G, et al. Combination of metformin and gefitinib as first-line therapy for non-diabetic advanced NSCLC patients with EGFR mutations: A randomized, double-blind phase 2 trial. Clin Cancer Res. 2019; 25: 6967-75.

28. Arrieta O, Barrón F, Padilla MS, Avilés-Salas A, Ramírez-Tirado LA, Arguelles Jiménez MJ, et al. Effect of Metformin Plus Tyrosine Kinase Inhibitors Compared With Tyrosine Kinase Inhibitors Alone in Patients With Epidermal Growth Factor Receptor-Mutated Lung Adenocarcinoma: A Phase 2 Randomized Clinical Trial. JAMA Oncol 2019 [Epub ahead of print]. doi: 10.1001/jamaoncol.2019; 2553.

29. Martin-Castillo B, Pernas S, Dorca J, Álvarez I, Martínez S, Pérez-Garcia $\mathrm{JM}$, et al. A phase 2 trial of neoadjuvant metformin in combination with trastuzumab and chemotherapy in women with early HER2-positive breast cancer: the METTEN study. Oncotarget. 2018; 8: 35687-704.

30. El-Fatatry BM, Ibrahim OM, Hussien FZ, Mostafa TM. Role of metformin in oxaliplatin-induced peripheral neuropathy in patients with stage III colorectal cancer: randomized, controlled study. Int J Colorectal Dis. 2018; 33: 1675-83

31. Moher D, Liberati A, Tetzlaff J, Altman DG; PRISMA Group. Preferred reporting items for systematic reviews and meta-analyses: the PRISMA statement. BMJ. 2009; 339: b2535.

32. Panic N, Leoncini E, de Belvis G, Ricciardi W, Boccia S. Evaluation of the endorsement of the preferred reporting items for systematic reviews and meta-analysis (PRISMA) statement on the quality of published systematic review and meta-analyses. PLoS One. 2013; 8: e83138.

33. Parmar MK, Torri V, Stewart L. Extracting summary statistics to perform meta-analyses of the published literature for survival endpoints. Stat Med. 1998; 17: 2815-34.

34. Wald NJ, Bestwick JP. Presentation of meta-analysis plots. J Med Screen. 2015; 22: 49-51.

35. Sterne JA, Sutton AJ, Ioannidis JP, Terrin N, Jones DR, Lau J, et al. Recommendations for examining and interpreting funnel plot asymmetry in meta-analyses of randomised controlled trials. BMJ. 2011; 343: d4002.

36. Eagger M, Davey Smith G, Schneider M, Minder C. Bias in meta-analysis detected by a simple graphical test. BMJ 1997; 315:629-634.

37. Jadad AR, Moore RA, Carroll D, Jenkinson C, Reynolds DJ, Gavaghan DJ, et al. Assessing the quality of reports of randomized clinical trials: is blinding necessary? Control Clin Trials. 1996; 17: 1-12.

38. Howell JJ, Hellberg K, Turner M, Talbott G, Kolar MJ, Ross DS, et al. Metformin Inhibits hepatic mTORC1 signaling via dose-dependent mechanisms involving AMPK and the TSC complex. Cell Metab. 2017; 25: 463-71.

39. Chandel NS, Avizonis D, Reczek CR, Weinberg SE, Menz S, Neuhaus R, et al. Are metformin doses used in murine cancer models clinically relevant? Cell Metab. 2016; 23: 569-70.

40. Gong J, Kelekar G, Shen J, Shen J, Kaur S, Mita M. The expanding role of metformin in cancer: an update on antitumor mechanisms and clinical development. Target Oncol. 2016; 11: 447-67.

41. Hardie DG. AMP-activated protein kinase as a drug target. Annu Rev Pharmacol Toxicol. 2007; 47: 185-210.

42. Hadad SM, Fleming S, Thompson AM. Targeting AMPK: a new therapeutic opportunity in breast cancer. Crit Rev Oncol Hematol. 2008; 67: 1-7.

43. Wang Z, Lai ST, Xie L, Zhao JD, Ma NY, Zhu J, et al. Metformin is associated with reduced risk of pancreatic cancer in patients with type 2 diabetes mellitus: a systematic review and meta-analysis. Diabetes Res Clin Pract. 2014; 106: 19-26.

44. Zhou PT, Li B, Liu FR, Zhang MC, Wang Q, Li YY, et al. Metformin is associated with survival benefit in pancreatic cancer patients with 
diabetes: a systematic review and meta-analysis. Oncotarget. 2017; 8: 25242-50.

45. Jian-Yu E, Graber JM, Lu SE, Lin Y, Lu-Yao G, Tan XL. Effect of Metformin and Statin Use on Survival in Pancreatic Cancer Patients: a Systematic Literature Review and Meta-analysis. Curr Med Chem. 2018; 25: 2595-607.

46. Morgillo F, Sasso FC, Della Corte CM, Vitagliano D, D'Aiuto E, Teresa T, et al. Synergistic effects of metformin treatment in combination with gefitinib, a selective EGFR tyrosine kinase inhibitor, in LKB1 wild-type NSCLC cell lines. Clin Cancer Res. 2013; 19: 3508-19.

47. Chen H, Yao W, Chu Q, Han R, Wang Y, Sun J, et al. Synergistic effects of metformin in combination with EGFR-TKI in the treatment of patients with advanced non-small cell lung cancer and type 2 diabetes. Cancer Lett. 2015; 369: 97-102.

48. Li L, Han R, Xiao H, Wang Y, Liu H, Liu K, et al. Metformin sensitizes EGFR-TKI-resistant human lung cancer cells in vitro and in vivo through inhibition of IL-6 signaling and EMT reversal. Clin Cancer Res. 2014; 20: 2714-26.

49. Suissa S, Azoulay L. Metformin and the risk of cancer: time-related biases in observational studies. Diabetes Care. 2012; 35:2665-73.

50. Pollak M. Overcoming drug development bottlenecks with repurposing: repurposing biguanides to target energy metabolism for cancer treatment. Nat Med. 2014; 20: 591-3.

51. Yang YX, Rustgi AK. Impact of Metformin on advanced pancreatic cancer survival: too little, too late? Clin Cancer Res. 2016; 22: 1031-3.

52. Wink KC, Belderbos JS, Dieleman EM, Rossi M, Rasch CR, Damhuis RA, et al. Improved progression free survival for patients with diabetes and locally advanced non-small cell lung cancer (NSCLC) using metformin during concurrent chemoradiotherapy. Radiother Oncol. 2016; 118: 453-9.

53. Coyle C, Cafferty FH, Vale C, Langley RE. Metformin as an adjuvant treatment for cancer: a systematic review and meta-analysis. Ann Oncol. 2016; 27: 2184-95. 